\title{
Management of twin-twin transfusion syndrome
}

\author{
Markus Hoopmann • Harald Abele • \\ Diethelm Wallwiener $\cdot$ Karl Oliver Kagan
}

Received: 22 January 2010 / Accepted: 12 February 2010/Published online: 25 March 2010

(C) Springer-Verlag 2010

\begin{abstract}
This paper presents a review of the diagnosis and treatment of twin-to-twin transfusion syndrome (TTTS). The incidence of fetal or neonatal mortality and preterm delivery in monochorionic twin pregnancies is substantially much higher than in dichorionic twin pregnancies due to TTTS. About $15 \%$ of all monochorionic twin pregnancies are affected by severe TTTS which is characterized by hypervolemia and polyhydramnios in one fetus and hypovolemia and anhydramnios in the other one. It is caused by vascular anastomoses within the shared placental system. With close surveillance without intervention, the majority of these pregnancies result in fetal death of both fetuses. Effective treatment is provided by intrauterine laser coagulation of the communicating vessels, allowing survival of at least one fetus in about $75 \%$ of the cases.
\end{abstract}

Keywords Fetoscopic laser coagulation - Twin-to-twin transfusion syndrome $\cdot$ Amnioreduction

\section{Introduction}

The incidence of fetal or neonatal death and preterm delivery in monochorionic twin pregnancies is substantially higher than in dichorionic twins and in singleton pregnancies $[1,2]$. The combined data of two ultrasound screening studies showed that, in twins where both fetuses were alive in the first trimester, there was subsequent miscarriage or spontaneous death of at least one fetus before 24 weeks of

\footnotetext{
M. Hoopmann $\cdot$ H. Abele $\cdot$ D. Wallwiener $\cdot$ K. O. Kagan $(\bowtie)$

Department of Obstetrics and Gynaecology,

University of Tuebingen,

Calwer Straße 7,

72076 Tübingen, Germany

e-mail: KOKagan@gmx.de
}

gestation in about $12 \%$ of monochorionic compared to $2.5 \%$ of dichorionic pregnancies $[1,3]$.

In a recent prospective observational study of two centres that specialized in the management of monochorionic twin pregnancies, the pregnancy resulted in two lifeborn infants in $85 \%$ of the cases. In $7.5 \%$ of the pregnancies, there was only one survivor [4]. In about $80 \%$ of those cases that were complicated by intrauterine demise, fetal death occurred before 24 weeks of gestation. Besides intrauterine demise, the risk for preterm delivery before 32 weeks is about doubled ( $9 \%$ versus 5.5\%) and the risk for intrauterine growth restriction of both fetuses is about four times higher $(7.5 \%$ versus $1.7 \%)$ in monochorionic twins. In case of intrauterine death of one fetus, the co-twin is at risk of acute exsanguination which can result in fetal death and severe mental handicap. A recent review of 4,500 twin pregnancies with fetal death of one fetus showed that, in the case of monochorionicity, the risk of fetal death for the co-twin was $12 \%$ versus $4 \%$ in dichorionic twins and the risk of neurological sequelae was $18 \%$ versus $1 \%$ [5].

The much higher morbidity in monochorionic compared to dichorionic twins has been attributed to complications arising mainly from twin-to-twin transfusion syndrome (TTTS) and disproportionate placental sharing.

\section{Pathophysiology}

In TTTS, imbalanced flow mainly over arterio-venous anastomoses leads to hypervolemia in one (recipient) and hypovolemia in the other fetus (donor). This shift is caused by the architecture of the vessels on the surface of the placenta. In all monochorionic twin pregnancies, there are arterio-arterial, veno-venous and arterio-venous anastomoses between the two vascular systems. It is the latter, often 
named "deep" anastomoses, which are responsible for a continuous increased net flow from the donor towards the recipient, leading to hypo- and hypervolemia in the respective twin $[6,7]$. Hypervolemia in the recipient causes an increased renal blood flow, polyuria and polyhydramnios which is the most striking symptom of the recipient in TTTS. Furthermore, the recipient is at risk of developing progressive cardiomyopathy. This includes cardiac dysfunction, artrioventricular valve regurgitation, pulmonary outflow obstruction, abnormal blood flow in the ductus venosus and, finally, hydrops fetalis. The donor is characterized by hypovolemia and oligo-/anhydramnios. This is often associated with an empty bladder, growth restriction and abnormal Doppler flow in the umbilical artery [8].

In most monochorionic pregnancies, interfetal transfusion through arterio-venous anastomoses is generally balanced and only about $15 \%$ of the monochorionic twin pregnancies are complicated by severe TTTS. Dynamic changes in the network of the shared placental vessels are suspected to be the main source. According to the hypothesis of "asymmetric reduction in placental anastomoses", there is a large number of bidirectional arterio-venous connections in all monochorionic twins in early pregnancy but with advancing gestation, progressive spontaneous closure or disruption of these anastomoses occurs at random [9, 10]. Besides vascular anastomoses as pathophysiological link to TTTS, placental dysfunction, dysregulation of natriuretic peptides and overexpression of the renin-angiotensin system are also likely to be involved [11-13].

\section{Clinical features}

In most cases, the classical picture of TTTS occurs between 16 and 24 weeks of gestation. The clinical course can be summarized by the Quintero classification, which is widely used [14]. Although this classification does not include all relevant features of TTTS, it defines prognostic subgroups according to the severity of the disease.

Quintero stage I, which is the mildest form of TTTS, only involves discordance of the amniotic fluid with polyhydramnios in the recipient and oligohydramnios in the donor twin. The bladder of the donor is still visible (Fig. 1). In Quintero stage II, the donor twin becomes "stuck" without bladder filling (Fig. 2). In stage III, fetal Doppler flow is abnormal. In the donor twin, there is absent or reversed end-diastolic flow in the umbilical artery, and in the recipient there is absent or reversed flow in the ductus venosus (Fig. 3). Fetal hydrops characterize stage IV and fetal death stage $V$, respectively.

Wee and Fisk suggested that a rapid progression to a higher stage is the best predictor of poor outcome [15]. Kagan et al. showed that discordance in the nuchal translucency thickness of the two twins at 11 to 14 weeks of gestation can be used to predict TTTS. A discordance of more than $20 \%$ increases the risk of severe TTTS, necessitating intrauterine therapy to $30 \%$, whereas the risk is less than $10 \%$ if the discordance is less than $20 \%$ [16]. Other risk factors for the development of severe TTTS are membrane folding at 15-17 weeks, the absence of arterioarterial anastomoses and velamentous cord insertion.

\section{Management of TTTS}

Treatment of TTTS depends on the severity of the disease. In Quintero stage I, the best approach is expectant management of the pregnancy, under close surveillance. In a study of O'Donoughue et al., about $70 \%$ of these cases remained unchanged in stage I or regressed without

Fig. 1 Quintero stage I with

discordance in amniotic fluid.

Both bladders are still visible

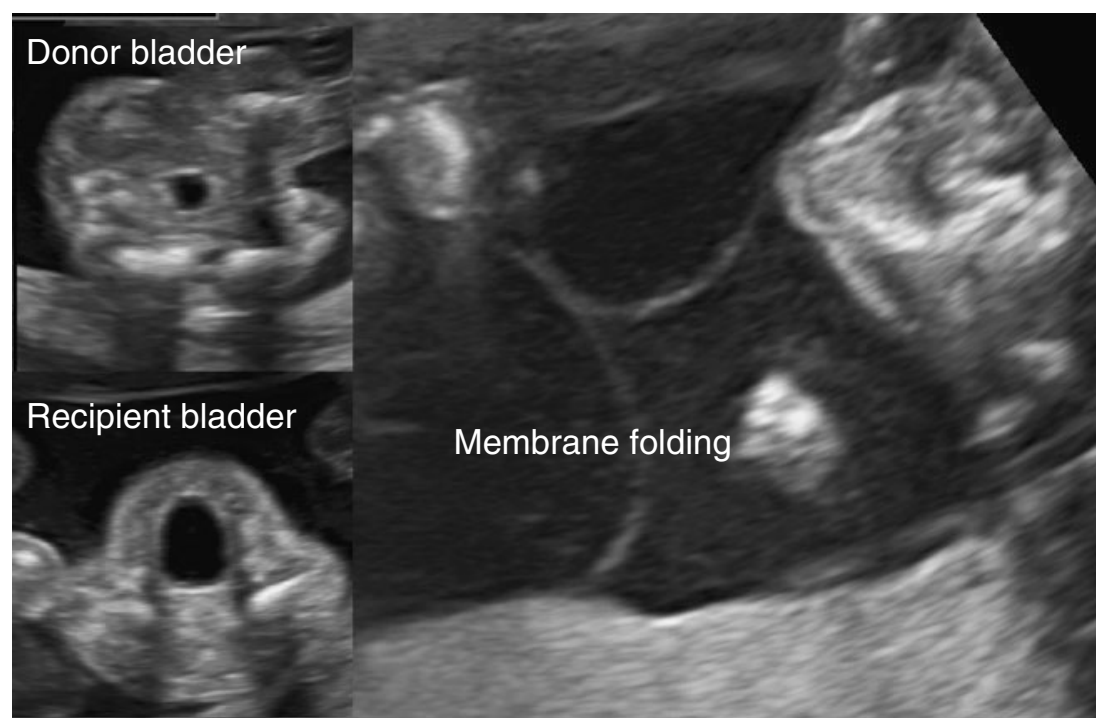




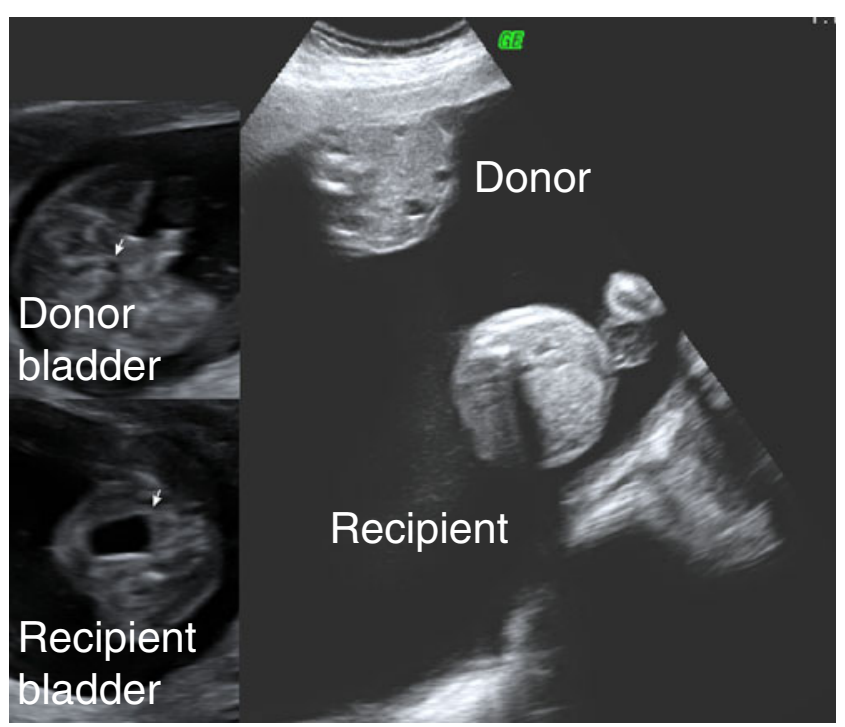

Fig. 2 Quintero stage II with polyhydramnios-anhydramnios sequence. The bladder of the donor is not visible whereas it is extended in the recipient

intervention [17]. In cases where the discordance of the amniotic fluid volume is more severe (donor: deepest pool less than $2 \mathrm{~cm}$; recipient: deepest pool more than $8-10 \mathrm{~cm}$ ) or if the criteria of Quintero stage II or worse are met, intervention is necessary to reduce fetal mortality and morbidity. The mortality rate of these severe cases has traditionally been quoted to be more than $80 \%$, although with improvements in neonatal care it may have been less [18]. Numerous therapeutic options have been proposed including serial amnioreduction, microseptostomy of the intertwin membrane, selective/nonselective fetoscopic laser photocoagulation and selective fetocide.

Serial amniodrainage is relatively simple and widely available. The aim is to reduce the polyhydramnios of the recipient to decrease the intrauterine pressure, to improve the utero-placental perfusion and to disburden the uterine cervix. However, the cause of the disease-anastomoses between the two vascular systems - and the risk of fetal demise and neurological damage of the co-twin in case of the intrauterine death of one fetus is not addressed. Available data suggest that amniodrainage is only effective in mild cases of TTTS and therapy failure is as high as one in three [18]. Septostomy was also not helpful in reducing fetal death [19]. Selective fetocide involves cord occlusion of one fetus, thereby stopping the circulation between the two fetuses in order to prevent double intrauterine death in cases of progressed TTTS. Selective termination of pregnancy is ethically controversial. Furthermore, it is hard to define which fetus is more affected and has the worse prognosis. In the recent prospective study of Lewi et al., in 18 cases with TTTS six cord occlusions were performed. The survival rate of the six co-twins was 50\% [4].

Endoscopic laser coagulation of the communicating anastomoses was introduced in the early 1990s with the intention of treating the primarily pathogenic cause of TTTS. The surgery is performed using a fetoscope of $20-30 \mathrm{~cm}$ in length and $1.0-2.3 \mathrm{~mm}$ in diameter. The scopes are used within a sheath housing the endoscope and the laser fiber for photocoagulation. After introduction in the amniotic cavity of the recipient, the cord insertion of the recipient needs to be identified. Following the vessels towards the donor leads to the equator between the vascular systems. The equator may be near to the intertwin membrane, although this is not always the case and it can also be pushed to the side of the donor. In the case of a posterior placenta, detection of the responsible vessels is easier. With an anterior placenta, visualization is more difficult and curved fetoscopes may be used [20]. After
Fig. 3 Quintero stage III with reversed flow in the ductus venosus of the recipient and reversed flow in the umbilical artery of the donor




identification of the anastomoses, laser coagulation is performed. The aim is to coagulate all communicating vessels in order to avoid exsanguination in case of a single fetal death. In about one third of cases, a total obliteration cannot be achieved but coagulation of majority of the communicating vessels often seems to be sufficient to stop the progression of TTTS. The generally used laser devices are Nd:YAG systems or diode lasers. Both systems are used in a continuous mode in a noncontact technique with about 50-80 W for the Nd:YAG system and 5-15 W for the diode laser (940 $\mathrm{nm}$ wavelength) [21, 22].

The surgery lasts about 30-60 min and can be performed under local or regional anesthesia. Due to smaller effects on maternal circulation and less frequent intraamniotic bleeding, regional anesthesia seems to be the safer technique [23]. The procedure is completed by amniodrainage until the amniotic fluid volume of the recipient is in the lower normal range.

The most relevant post-surgical problem is premature rupture of membranes (PROM) which complicates about 10\% of all treated pregnancies [11]. In a recent report of a single centre experience with 152 laser treatments, the authors report a PROM rate of $8 \%$ within 7 days after the procedure and $17.8 \%$ after 7 days of procedure, respectively. Another complication that may occur during the course of the pregnancy after laser surgery is iatrogenic twin anemiapolycythemia sequence (TAPS). It is reported to occur in up to $13 \%$ of the cases and may necessitate intrauterine transfusion $[24,25]$. The pathophysiology is not finally elucidated. It can be explained as a shunt over persistent small anastomes after laser surgery. Others interpret the complication as an aggravation of a residual, isovolemic haemoglobin discordance by equalization of the amnion fluid amounts.

In a recent meta-analysis including the Eurofetus study, 432 pregnancies treated by laser were compared with 179 pregnancies treated with amniodrainage [23]. Overall, survival rate was $57-77 \%$ by laser and $38-81 \%$ by amnioreduction. Neonatal death occurred in $4-12 \%$ of the cases treated by laser and in $14-39 \%$ of those treated by amnioreduction. Cerebral anomalies were observed in 2-33\% after laser and in $18-83 \%$ after amnioreduction. Fetuses undergoing laser treatment were twice as likely to survive as fetuses undergoing amniodrainage and five times less likely to suffer from neurologic morbidity. Graef et al. examined the longterm neurodevelopmental outcome after laser coagulation for TTTS. Of 167 children examined at an infant age of about 3 years, $87 \%$ had no neurological impairment and only $6 \%$ had major neurologic abnormalities [26].

\section{Conclusion}

Severe TTTS complicates about $15 \%$ of all monochorionic twin pregnancies. The gold standard of therapy is feto- scopic laser coagulation of communicating vessels. It is the only therapeutic option targeting on the pathophysiological cause of TTTS and having curative intention for both twins. Amniodrainage cannot achieve survival rates of laser therapy and neurological sequelae are more frequent. The most relevant complications of laser therapy are PROM and TAPS.

Conflict of interest No payment or support was received in kind for any aspect of the submitted work (including but not limited to grants, data monitoring board, study design, manuscript preparation, statistical analysis, etc.). There have been no financial relationships (regardless of amount of compensation) with any entities that have an interest related to the submitted work. There have been no nonfinancial associations or interests (personal, professional, political, institutional, religious or others) that a reasonable reader would want to know about in relation to the submitted work.

\section{References}

1. Sebire NJ, Snijders RJ, Hughes K, Sepulveda W, Nicolaides KH (1997) The hidden mortality of monochorionic twin pregnancies. Br J Obstet Gynaecol 104(10):1203-1207

2. Acosta-Rojas R, Becker J, Munoz-Abellana B, Ruiz C, Carreras E, Gratacos E (2007) Twin chorionicity and the risk of adverse perinatal outcome. Int J Gynaecol Obstet 96(2):98-102

3. Sperling L, Kiil C, Larsen LU, Qvist I, Schwartz M et al (2006) Naturally conceived twins with monochorionic placentation have the highest risk of fetal loss. Ultrasound Obstet Gynecol 28 (5):644-652

4. Lewi L, Jani J, Blickstein I, Huber A, Gucciardo L, Van Mieghem T, Doné E, Boes AS, Hecher K, Gratacós E, Lewi P, Deprest J (2008) The outcome of monochorionic diamniotic twin gestations in the era of invasive fetal therapy: a prospective cohort study. Am J Obstet Gynecol 199(5):514.e1-514.e8

5. Ong SS, Zamora J, Khan KS, Kilby MD (2006) Prognosis for the co-twin following single-twin death: a systematic review. Bjog 113(9):992-998

6. Lewi L, Cannie M, Blickstein I, Jani J, Huber A, Hecher K, Dymarkowski S, Gratacós E, Lewi P, Deprest J (2007) Placental sharing, birthweight discordance, and vascular anastomoses in monochorionic diamniotic twin placentas. Am J Obstet Gynecol 197(6):587.e1-587.e8

7. Diehl W, Hecher K, Zikulnig L, Vetter M, Hackelöer BJ (2001) Placental vascular anastomoses visualized during fetoscopic laser surgery in severe mid-trimester twin-twin transfusion syndrome. Placenta 22(10):876-881

8. Huber A, Hecher K (2004) How can we diagnose and manage twin-twin transfusion syndrome? Best Pract Res Clin Obstet Gynaecol 18(4):543-556

9. Sebire NJ, Talbert D, Fisk NM (2001) Twin-to-twin transfusion syndrome results from dynamic asymmetrical reduction in placental anastomoses: a hypothesis. Placenta 22(5):383-391

10. Galea P, Jain V, Fisk NM (2005) Insights into the pathophysiology of twin-twin transfusion syndrome. Prenat Diagn 25 (9):777-785

11. Lewi L, Van Schoubroeck D, Gratacos E, Witters I, Timmerman D et al (2003) Monochorionic diamniotic twins: complications and management options. Curr Opin Obstet Gynecol 15(2):177194 
12. Bajoria R, Ward S, Chatterjee R (2002) Natriuretic peptides in the pathogenesis of cardiac dysfunction in the recipient fetus of twintwin transfusion syndrome. Am J Obstet Gynecol 186(1):121-127

13. Kilby MD, Platt C, Whittle MJ, Oxley J, Lindop GB (2001) Renin gene expression in fetal kidneys of pregnancies complicated by twintwin transfusion syndrome. Pediatr Dev Pathol 4(2):175-179

14. Quintero RA, Morales WJ, Allen MH, Bornick PW, Johnson PK et al (1999) Staging of twin-twin transfusion syndrome. J Perinatol 19(8 Pt 1):550-555

15. Wee LY, Fisk NM (2002) The twin-twin transfusion syndrome. Semin Neonatol 7(3):187-202

16. Kagan KO, Gazzoni A, Sepulveda-Gonzalez G, Sotiriadis A, Nicolaides KH (2007) Discordance in nuchal translucency thickness in the prediction of severe twin-to-twin transfusion syndrome. Ultrasound Obstet Gynecol 29(5):527-532

17. O'Donoghue K, Cartwright E, Galea P, Fisk NM (2007) Stage I twin-twin transfusion syndrome: rates of progression and regression in relation to outcome. Ultrasound Obstet Gynecol 30(7):958-964

18. van Gemert MJ, Umur A, Tijssen JG, Ross MG (2001) Twin-twin transfusion syndrome: etiology, severity and rational management. Curr Opin Obstet Gynecol 13(2):193-206

19. Roberts D, Gates S, Kilby M, Neilson JP (2008) Interventions for twin-twin transfusion syndrome: a Cochrane review. Ultrasound Obstet Gynecol 31(6):701-711

20. Huber A, Baschat AA, Bregenzer T, Diemert A, Tchirikov M, Hackelöer BJ, Hecher K (2008) Laser coagulation of placental anastomoses with a 30 degrees fetoscope in severe mid-trimester twin-twin transfusion syndrome with anterior placenta. Ultrasound Obstet Gynecol 31(4):412-416

21. Luks FI, Carr SR, Muratore CS, O'Brien BM, Tracy TF (2009) The pediatric surgeons' contribution to in utero treatment of twinto-twin transfusion syndrome. Ann Surg 250(3):456-462

22. Bussey JG, Luks F, Carr SR, Plevyak M, Tracy TF Jr (2004) Minimal-access fetal surgery for twin-to-twin transfusion syndrome. Surg Endosc 18(1):83-86

23. Rossi AC, D'Addario V (2008) Laser therapy and serial amnioreduction as treatment for twin-twin transfusion syndrome: a metaanalysis and review of literature. Am J Obstet Gynecol 198 (2): $147-152$

24. Robyr R, Lewi L, Salomon LJ, Yamamoto M, Bernard JP, Deprest J, Ville Y (2006) Prevalence and management of late fetal complications following successful selective laser coagulation of chorionic plate anastomoses in twin-to-twin transfusion syndrome. Am J Obstet Gynecol 194(3):796-803

25. Herway C, Johnson A, Moise K, Moise KJ Jr (2009) Fetal intraperitoneal transfusion for iatrogenic twin anemia-polycythemia sequence after laser therapy. Ultrasound Obstet Gynecol 33 (5):592-594

26. Graef C, Ellenrieder B, Hecher K, Hackeloer BJ, Huber A, Bartmann P (2006) Long-term neurodevelopmental outcome of 167 children after intrauterine laser treatment for severe twin-twin transfusion syndrome. Am J Obstet Gynecol 194(2):303-308 